\title{
Application of Brown Cotton-Supported Palladium Nanoparticles in Suzuki-Miyaura Cross-Coupling Reactions
}

\author{
Michael W. Easson, * Jacobs H. Jordan, John M. Bland, Doug J. Hinchliffe, and Brian D. Condon \\ US Department of Agriculture, Agricultural Research Service, Southern Regional Research Center, 1100 Robert E. Lee \\ Blvd, LA 70124, USA *Email: Michael.Easson@usda.gov; Tel: 504-286-4493
}

Michael W. Easson - orcid.org/0000-0002-2268-1922;
Jacobs H. Jordan - orcid.org/0000-0002-0238-3864
John M. Bland - orcid.org/0000-0003-1167-7415
Doug J. Hinchliffe - orcid.org/0000-0002-5108-9661
Brian D. Condon - orcid.org/0000-0003-1944-021X

KEYWORDS: Catalysis, palladium, cotton, polyphenol, reducing agent, nanoparticle and Suzuki-Miyaura

\section{TABLE OF CONTENTS}

1. Table of Contents

2. Experimental Section

a. Materials

b. Preparation of palladium nanoparticles in nonwoven brown cotton fabric

c. X-ray Photoelectron Spectroscopy (XPS)

d. Scanning Electron Microscopy (SEM)

e. Transmission Electron Microscopy (TEM)

f. Inductively Coupled Plasma (ICP) Atomic Emission Spectrometry

g. Gas Chromatography-Mass Spectroscopy (GC-MS)

h. Suzuki-Miyaura Synthesis

i. NMR spectroscopy

j. Calculation of Turnover Frequency

3. Figures and Tables

Figure S1. TEM photomicrographs of untreated, Pd-treated brown cotton fibers

Figure S2. SEM photomicrographs of unwashed brown cotton fibers

Figure S3. XPS qualification of palladium nanoparticle binding energies

Scheme S1. List of reaction schemes and outcomes for Pd-catalyzed Suzuki couplings

Scheme S2. Minor products of reactions with two or more halide substituents 
Figure S4. Stack of (from bottom to top) starting materials (phenyl boronic acid, 4-iodo phenol), the authentic commercially supplied product (4-phenyl phenol), and the obtained product after 1-10 cycles using Pd catalyst within brown cotton fibers

Figure S5. ${ }^{1} \mathrm{H}$ NMR $\left(300 \mathrm{MHz}, \mathrm{CD}_{2} \mathrm{Cl}_{2}\right.$ ) of entry 2 product ( $p$-phenylphenol)

Figure S6. ${ }^{13} \mathrm{C}$ NMR $\left(75 \mathrm{MHz}, \mathrm{CD}_{2} \mathrm{Cl}_{2}\right)$ of entry 2 product ( $p$-phenylphenol)

Figure S7. Photos of the palladium nanoparticle-infused NBCF, before (left) and after (right) 10x Suzuki-coupling experiments

Figure S8. Average palladium ( $\mathrm{Pd}$ ) concentration from ICP-MS in unreacted and treated samples of fabric before (unreacted) and after 10 Suzuki-coupling experiments

Figure S9. Sample GC-MS trace for entry 2 scaled reaction

Figure S10. GC-MS traces for entry 12

Figure S11. GC-MS traces for entry 13 


\section{EXPERIMENTAL SECTION}

\section{a. Materials}

Palladium (II) chloride, boronic acid derivatives and aryl halide derivatives were purchased from Sigma Aldrich and used as received. Methylene chloride, hexane and ethyl acetate were purchased from Fisher Scientific and used without further purification. Nonwoven brown cotton fabric (NBCF) was manufactured at the United States Department of Agriculture's Southern Regional Research Center in New Orleans, Louisiana and used without further modification.

\section{b. Preparation of palladium nanoparticles in nonwoven brown cotton fabric}

$\mathrm{PdCl}_{2}(1.25 \mathrm{~g}, 7.50 \mathrm{mmol})$ was dissolved in deionized water $(1.5 \mathrm{~L})$ and nonwoven brown cotton fabric $(38.75 \mathrm{~g})$ was added. The mixture was heated to a boil and stirred rapidly for $2 \mathrm{~h}$. At $95{ }^{\circ} \mathrm{C}$ the aqueous liquid turned from brown to black. After boiling for $25 \mathrm{~min}$, the aqueous liquid turned from black to light golden and the brown cotton fabric turned black in color. After boiling for a total of $2 \mathrm{~h}$, the fabric was removed and repeatedly rinsed in boiling deionized water $(1.5 \mathrm{~L})$ until the liquid rinse was clear. The wet fabric was allowed to dry under ambient conditions.

\section{c. X-ray Photoelectron Spectroscopy (XPS)}

The XPS measurements were performed using a ScientaOmicron ESCA 2SR X-ray Photoelectron Spectroscope System equipped with a Flood Source Charge Neutralizer. The unwashed samples of treated cotton fibers were fixed on the sample stage with double-sided carbon tape and loaded into the XPS preparation chamber and pumped more than $8 \mathrm{~h}$ before they were transferred to the analysis chamber. All analysis were carried out with a Mono Al Ka X-ray source (1486.6 eV) at the power of 450 $\mathrm{W}$; the pressure in the analysis chamber was maintained below $3 \times 10^{-9}$ Torr. A survey scan and all elemental region scans were performed for each sample. All data were post-processed with Casa XPS software. All spectra were calibrated with C1s peak at $284.8 \mathrm{eV}$. Core level XPS spectra were deconvoluted to obtain chemical state information.

\section{d. Scanning Electron Microscopy (SEM)}

For SEM, samples were fixed on a SEM stub with double-sided Carbon tape, coated with Pt about 810 Å thick. SEM images were acquired on a FEI Quanta 3D FEG FIBSEM dual beam system. To minimize the beam damage on the cotton fibers, $5 \mathrm{kV}$ operating voltage and $3.0 \mathrm{pA}$ beam current were used to image the samples.

\section{e. Transmission Electron Microscopy (TEM)}


Cross-sections of cotton fiber were examined for gold and palladium nanoparticles using a TEM (JEOL 2010) operating at $200 \mathrm{kV}$. For the sample preparation, a bundle of combed fibers was embedded in a

mixture of methyl methacrylate and butyl methacrylate, which was polymerized using a UV cross-linker (UVP, CL-1000) for two days following the published technique. ${ }^{1}$ A block of the fiber bundle was cut into approximately $90 \mathrm{~nm}$-thick slices using a Leica EM UC7 Microtome (Boeckeler Instruments, Inc.). The obtained sections were placed on a carbon-film-coated copper grid, and the embedding medium was removed with methyl ethyl ketone. The optical microscopic images of samples were taken using a JEOL JEM-1400 transmission electron microscope. ImageJ software v. 1.52d (National Institutes of Health, Bethesda, MD, USA) was used for analysis of the particle diameter from greater than 100 observations. ${ }^{2}$ Results were fit with a Gaussian function using OriginPro2019 (v9.6) to determine the mean length (diameter) of the nanoparticles.

\section{f. Inductively Coupled Plasma (ICP) Mass Spectrometry}

Nonwoven brown cotton fabric samples prepared with palladium catalyst were analyzed for palladium content using an inductively coupled plasma emission spectrophotometer (ARCOS, Spectro Analytical Instruments) with the digestion of $0.2 \mathrm{~g}$ of sample in $9.0 \mathrm{~mL}$ of nitric acid. Additionally, the isolated reaction products from scaled reactions were analyzed for trace palladium that might have leached from the catalytic substrate.

\section{g. Gas Chromatography-Mass Spectrometry (GC-MS)}

Analysis was carried out on a GC model 6890 with MS model 5973 (Agilent 145 Technologies) fitted with an DB5-MS $(20 \mathrm{~m} \times 0.18 \mathrm{~mm}$ id., $0.18 \mu \mathrm{m}$ film) modular accelerated column heater (MACH) capillary column (Gerstel, Inc., Linthicum, MD). The MACH column heating was controlled by an integrated Gerstel Maestro software, beginning with a $1 \mathrm{~min}$ hold at $50{ }^{\circ} \mathrm{C}$, followed by a $12{ }^{\circ} \mathrm{C} / \mathrm{min}$ gradient to $300{ }^{\circ} \mathrm{C}$, with a $3.17 \mathrm{~min}$ hold at $300^{\circ} \mathrm{C}$. A helium flow rate of $0.7 \mathrm{~mL} / \mathrm{min}$ was maintained by a programmed pressure gradient in the Chemstation software $(14.8 \mathrm{psi}(1 \mathrm{~min}$ hold) to $33.6 \mathrm{psi}$ at $14.8 \mathrm{psi} / \mathrm{min}$, with a $3.17 \mathrm{~min}$ final hold. The oven and MS transfer temperatures were set at a constant $250{ }^{\circ} \mathrm{C}$. A quickswap was employed between the column and MS transfer, with a 3-psi flow of helium. An autosampler performed the GC injections, using a $1 \mu \mathrm{L}$ injection volume, into a splitless injector at $250{ }^{\circ} \mathrm{C}$. Data were collected and analyzed using the MSD ChemStation program (Rev.D.03.00.552; Agilent Technologies 1989-2006). Identification of peaks was by mass and halogen isotope patterns.

\section{h. Suzuki-Miyaura Synthesis}


In small-scale reactions, an aryl halide derivative $(0.50 \mathrm{mmol}, 1.0 \mathrm{eq})$, boronic acid $(0.75 \mathrm{mmol}, 1.50$ eq), base $\left(\mathrm{K}_{2} \mathrm{CO}_{3}\right.$ or $\mathrm{K}_{3} \mathrm{PO}_{4}, 1.50 \mathrm{mmol}, 3.0$ eq. $)$, solvent $\left(\mathrm{H}_{2} \mathrm{O} / \mathrm{EtOH}, 5 \mathrm{ml} / 5 \mathrm{~mL}\right)$ and palladium nanoparticle-impregnated NBCF $(0.021 \mathrm{~g}, 3.6 \mu \mathrm{mol} \mathrm{Pd}, 7.2 \mathrm{meq}$ ) were added to a $100 \mathrm{~mL}$ pressure resistant vial, which was sealed, heated to $80{ }^{\circ} \mathrm{C}$ and stirred for three hours. In large-scale reactions, an aryl halide derivative $(0.022 \mathrm{~mol}, 1.0 \mathrm{eq})$, boronic acid $(0.034 \mathrm{~mol}, 1.50 \mathrm{eq})$, base $\left(\mathrm{K}_{3} \mathrm{PO}_{4}, 0.068 \mathrm{~mol}, 3.0\right.$ eq), $500 \mathrm{~mL} \mathrm{H} \mathrm{H}_{2} \mathrm{O}-\mathrm{EtOH}$ (1:1) and palladium nanoparticle-impregnated NBCF (0.100 g, $17.10 \mu \mathrm{mol}$ Pd, $0.78 \mathrm{meq}$ ) were added to a $1 \mathrm{~L}$ three-necked round bottom flask equipped with a condenser, sealed, heated to $80^{\circ} \mathrm{C}$ and stirred for $3 \mathrm{~h}$.

After the reaction, it was cooled to rt and the ethanol was removed under reduced pressure. The crude material was poured into a separatory funnel, deionized water $(200 \mathrm{~mL})$ and brine $(50 \mathrm{~mL})$ was added, and the product was extracted with either hexane, ethyl acetate, or methylene chloride $(3 \times 75 \mathrm{~mL})$, depending upon the polarity of the coupled product. The organic layer was dried over anhydrous sodium sulfate granules, filtered, and the solvent removed to afford the final product. No further purification was needed. Final cross-coupled products were confirmed by thin layer chromatography and GC-MS.

\section{i. NMR spectroscopy}

Reagents were purchased from commercial supplier Sigma-Aldrich Corp. and used without further purification. All ${ }^{1} \mathrm{H}$ NMR spectra were collected on a Bruker $300 \mathrm{MHz}$, or Varian $400 \mathrm{MHz}$ spectrometer at $23{ }^{\circ} \mathrm{C}$. The ${ }^{13} \mathrm{C}$ NMR spectra was collected on a Bruker $300 \mathrm{MHz}\left(75 \mathrm{MHz}{ }^{13} \mathrm{C}\right)$ spectrometer at $23^{\circ} \mathrm{C}$. All spectra utilized deuterated solvents (Cambridge Isotopes, 99.9\%+ and the chemical shifts $(\delta)$ were referenced to the residual solvent signal. Spectral processing was performed using MNova software $v$. 11.0 (Mestrelab Research, S.L.).

\section{j. Calculation of Turnover frequency}

The Turnover frequency (TOF) is the turnover number expressed per unit time. The TOF of the active catalyst was calculated by the methods employed previously ${ }^{3-4}$ and is simply the moles of the expected product / active sites / reaction time (h). To determine the number of active sites on a spherical NP, the number of surface Pd atoms per NP, the number of NPs and finally the number of active sites per reaction must be calculated.

Number of Pd atoms (active sites) on the surface of a nanoparticle: 
The lattice constant of a face-centered-cubic Pd nanocrystal is $0.389 \mathrm{~nm}$ and the volume of the unit cell is $(0.389 \mathrm{~nm})^{3}=0.059 \mathrm{~nm}^{3}$. Each unit cell of Pd contains four Pd atoms. Each PdNP has a diameter of $7.9 \mathrm{~nm}$ and a radius $(r)$ of $3.95 \mathrm{~nm}$. The volume $(V)$ of a PdNP sphere is:

$$
V=\frac{4}{3} \pi r^{3} \approx 258.2 \mathrm{~nm}^{3}
$$

Therefore, there are $17542 \mathrm{Pd}$ atoms per NP:

$$
\frac{258.2 \mathrm{~nm}^{3}}{0.059 \mathrm{~nm}^{3} / \text { unitcell }} \times 4^{\text {atoms }} / \text { unitcell } \approx 17542^{\text {atoms }} / \mathrm{NP}
$$

Given that any one face of the unit cell can face the surface of the NP, then there are two Pd atoms per surface are unit cell which is $(0.389)^{2}=0.15 \mathrm{~nm}^{2}$. The surface area of the NP sphere is given by:

$$
S A=4 \pi r^{2} \approx 196 \mathrm{~nm}^{2}
$$

The number of Pd atoms (active sites) on the surface of each NP is given by the surface area of the sphere divided by the surface exposed unit cells times the number of $\mathrm{Pd}$ atoms per unit cell surface:

$$
\frac{196 \mathrm{~nm}^{2}}{0.15 \mathrm{~nm}^{2}} \times 2 \text { atoms } \approx 2591^{\text {sites }} / \mathrm{NP}
$$

\section{Number of active sites in the reaction}

Given the typical $0.021 \mathrm{~g} \mathrm{NBCF}$ in the reaction and the molecular mass of Pd $(106.42 \mathrm{~g} / \mathrm{mol})$ with a catalyst load of $18.2 \mathrm{mg} / \mathrm{g} \mathrm{Pd}$ in NBCF, then there were $\sim 0.3822 \mathrm{mg} \mathrm{Pd} /$ reaction, which is $\sim 3.6 \mu \mathrm{mol} \mathrm{Pd}$ in reaction. From this the number of atoms of $\mathrm{Pd}$ can be determined from Avagadro's number:

$$
3.6 \times 10^{-6} \mathrm{~mol}\left(6.02 \times 10^{23} \mathrm{atoms} \mathrm{mol}^{-}\right) \approx 2.16 \times 10^{18^{\text {atoms }} / \text { reaction }}
$$

Since there were $17,542 \mathrm{Pd}$ atoms per NP and there are $2.16 \times 10^{18} \mathrm{Pd}$ atoms per reaction, then there are $1.23 \times 10^{14} \mathrm{PdNP}$ per reaction: 


$$
\frac{2.16 \times 10^{18} \text { atoms } / \text { reaction }}{17542^{\text {atoms }} / N P} \approx 1.23 \times 10^{14} \mathrm{NP} / \text { reaction }
$$

Given the number of PdNP per reaction and the number of active sites per NP, it is then straightforward to determine the number of active sites and hence the number of moles of available Pd per reaction:

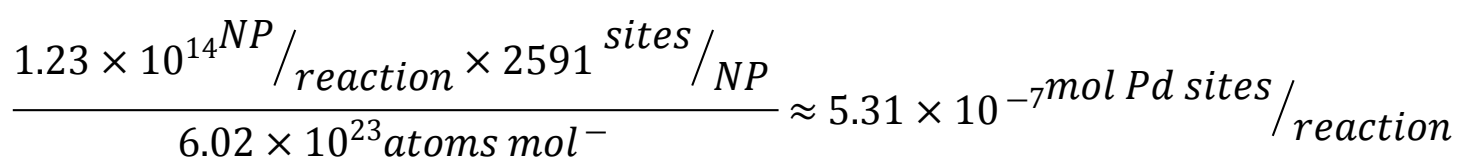




\section{Figures \& Tables}

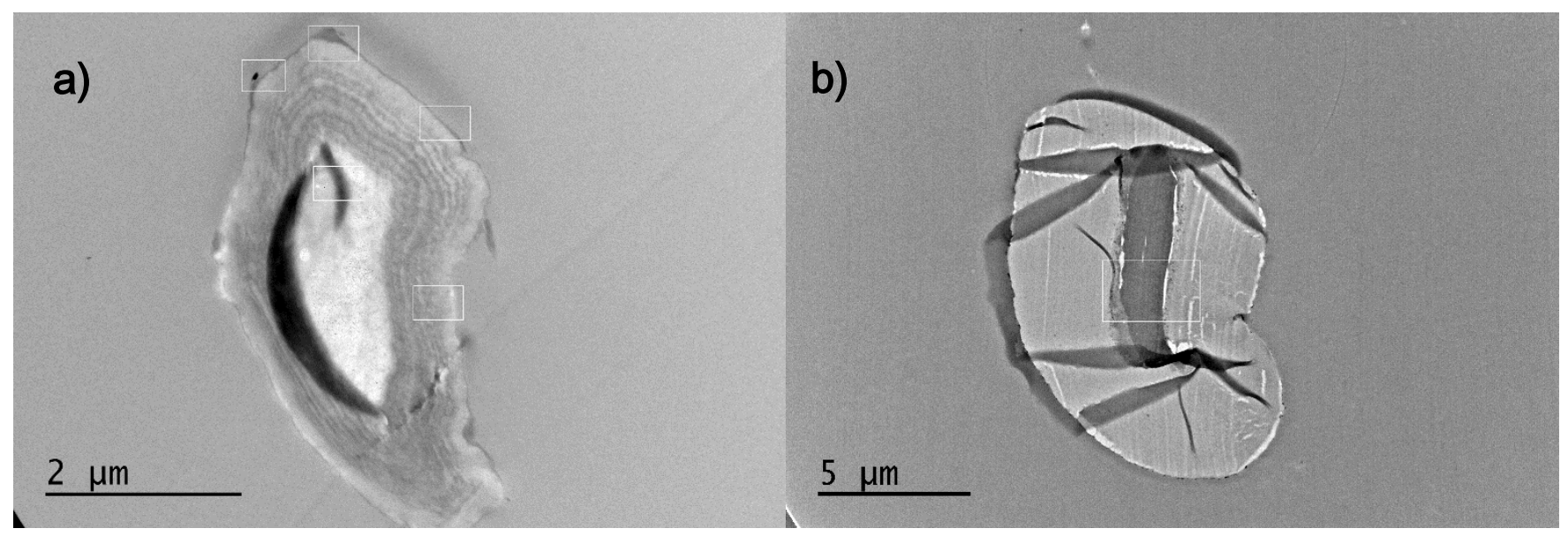

Figure S1. TEM photomicrographs of untreated, and Pd-treated brown cotton fibers: a) an untreated brown cotton fiber; b) a fiber after deposition of $\mathrm{Pd}$ nanoparticles (the boxed region shows the area shown in Figure $1 \mathrm{~d}$ of the main text)

There was a small amount of aggregation at the lumen of the NBCF-PdNP. These larger aggregates represent $<2 \%$ of the total on a number average bases, and hence do not significantly contribute to the shape of the histogram or the determined fit. Additionally, it has been shown that the activity of PdNP catalysts is size dependent and larger NP have significantly reduced activity. ${ }^{5}$ For these reasons, large (>20 nm) particles were not considered to be significant in terms of catalyst efficacy. Thus, this region was excluded from the histogram for particle size distribution.

Fibers that have been exhaustively washed contained no surface-bound nanoparticles. However, samples of unwashed fibers were analyzed by SEM/EDS and by XPS for their elemental composition. Pd aggregates are observed on the surface of unwashed fibers (Figure S2a). Focused Ion Beam (FIB) SEM was used to cross-section a fiber for EDAX and showed Pd was internalized into the fiber lumen (Figure S2b-c), and the EDS results confirm the presence of $\mathrm{Pd}$ ( $\mathrm{Ga}$ used to prepare samples for FIB EDAX results). 


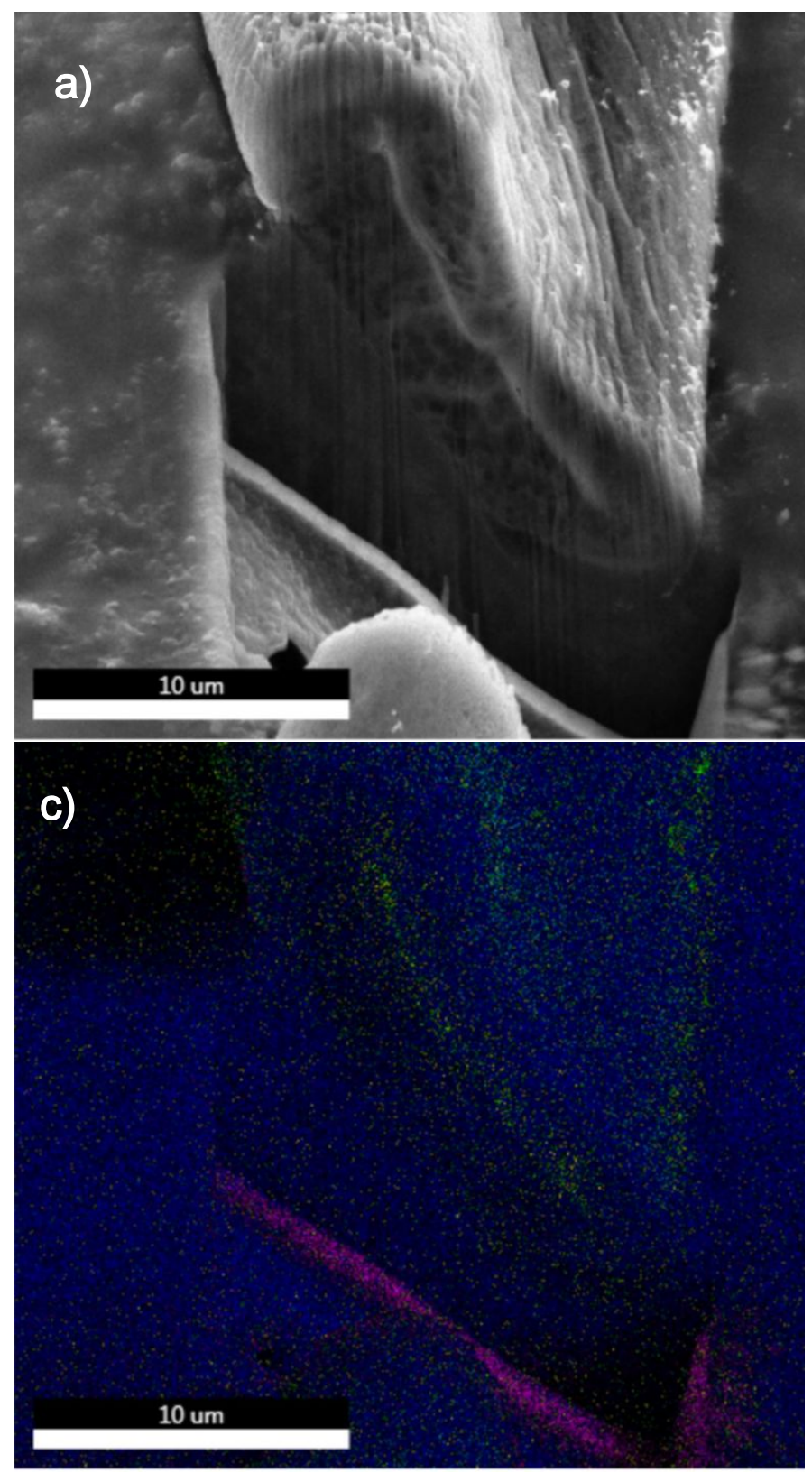



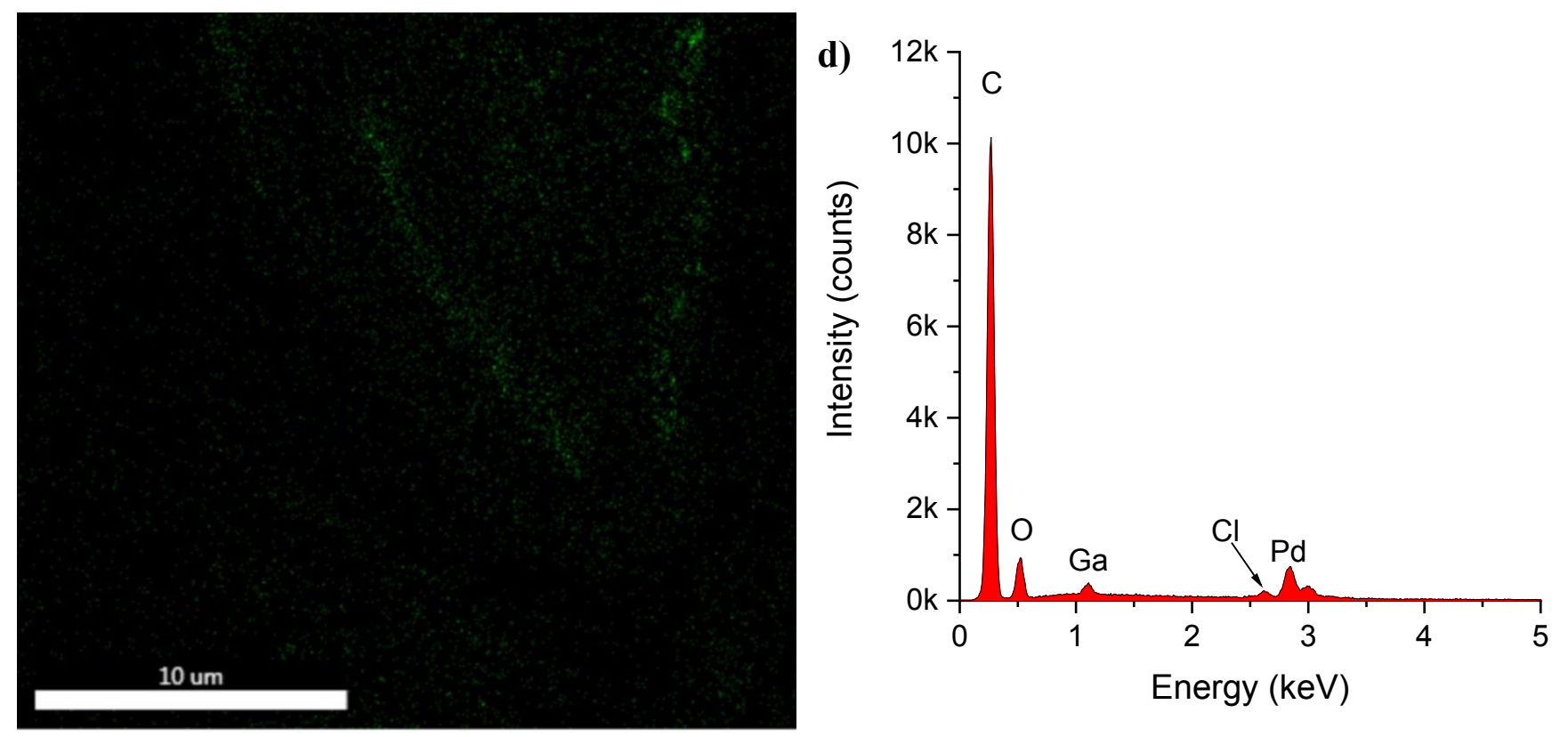

Figure S2. SEM photomicrographs of unwashed brown cotton fibers: a) FIB cross-section of brown cotton fiber containing Pd nanoparticles, b) EDS elemental mapping of (a) with C (blue) Cl (yellow) Pd (green) O (teal) and Ga (magenta), c) same image as (b) displaying only Pd seen inside the fiber lumen and some small aggregates on the fiber surface, and d) EDS plot of (b) showing the distribution of $\mathrm{C}, \mathrm{O}, \mathrm{Cl}, \mathrm{Pd}$, and $\mathrm{Ga}$

XPS was used to detect the elemental composition of brown cotton fibers (Figure S3) and the oxidation state of the cotton-bound metals. Since XPS is a surface sensitive technique, unwashed samples of the fibers after reaction were analyzed to obtain binding energies and confirmed that $\mathrm{Pd}^{2+}$ was reduced to $\mathrm{Pd}^{0}$, (Figure S3d). The peaks at 335.6 and 340.7 correspond to $\mathrm{Pd}^{0}$ while the peaks at 337.6 and 342.8 correspond to palladium(II) which may contain residual $\mathrm{PdCl}_{2}$ chloride from the aqueous reaction bath. There was a significant contribution from alkane $\mathrm{C}-\mathrm{C}$ and $\mathrm{C}-\mathrm{H}$ bonds at $284.2 \mathrm{eV}$, as well as $\mathrm{C}-\mathrm{O}$ bonds at 284.8, and $\mathrm{O}-\mathrm{C}-\mathrm{O}$ glycosidic linkages of cellulose or $\mathrm{C}=\mathrm{O}$ of oxidized tannins at 286.3 and ester $\mathrm{O}-$ $\mathrm{C}=\mathrm{O}$ bonds at $288.1 .^{6}$ 

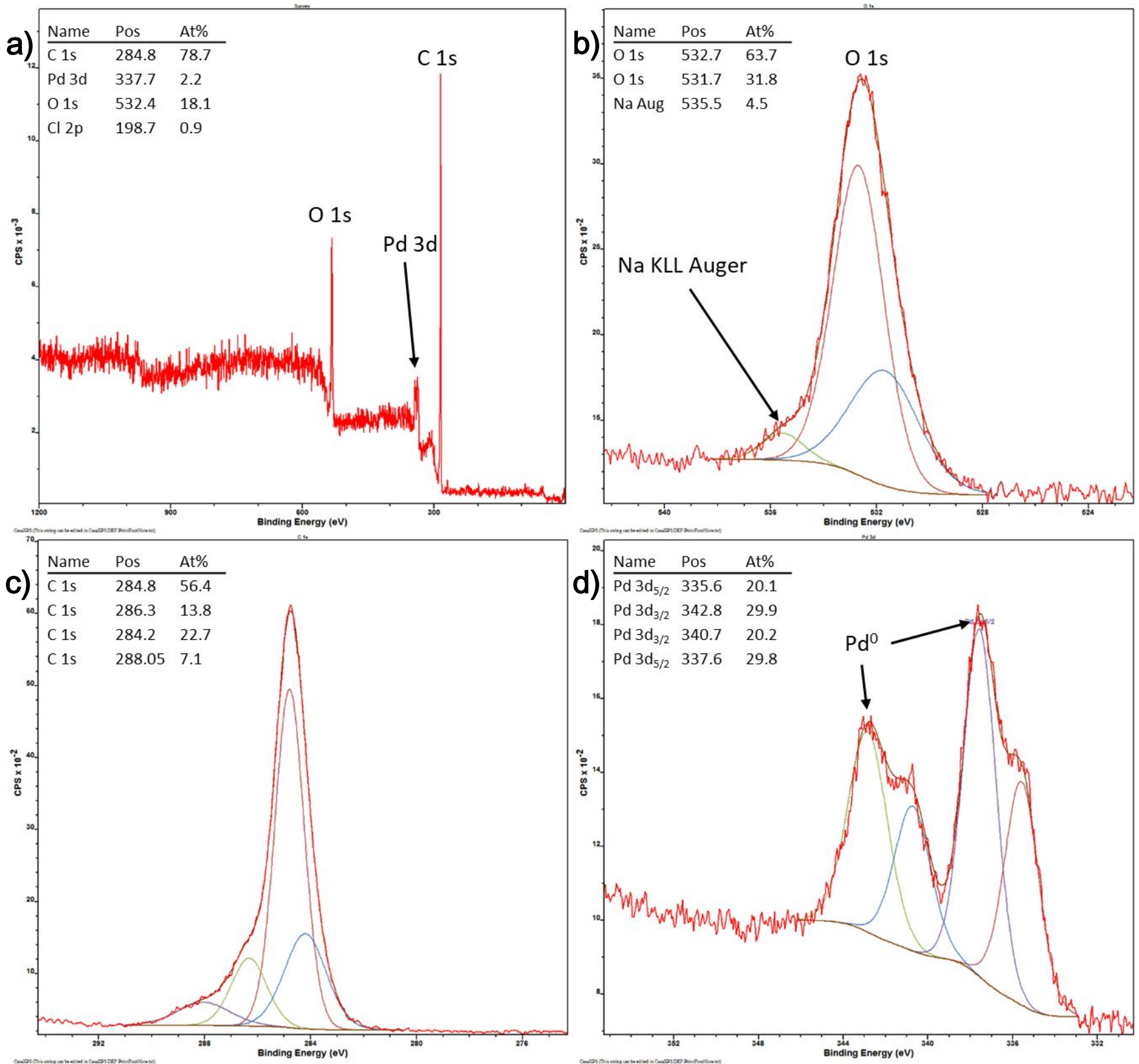

Figure S3. XPS qualification of palladium nanoparticle binding energies. a) survey scan; b) $O$ 1s region; c) $C$ 1s; and d) $\mathrm{Pd} 3 \mathrm{~d}(3 / 2)$ and (5/2). C, and $\mathrm{O}$ are from the cellulosic fibers and tannins. The peaks at 335.6 and 340.7 correspond to $\mathrm{Pd}^{0}$ while the peaks at 337.6 and 342.8 correspond to palladium(II) which may contain residual $\mathrm{PdCl}_{2}$ chloride from the aqueous reaction bath.

Examination of the $\mathrm{O}$ 1s region that had a contribution at a lower binding energy $531.7 \mathrm{eV}$ suggests a significant proportion of $\mathrm{C}=\mathrm{O}$ bonds. Native cellulose (and other polyphenols), contain mostly $\mathrm{C}-\mathrm{O}$ bonds which were observed at $532.7 \mathrm{eV}$. Reduction of $\mathrm{Pd}^{2+}$ to $\mathrm{Pd}^{0}$ and concomitant oxidation of the polyphenols resulted in a larger relative proportion in the observed signal. The small broad signal at $535.5 \mathrm{eV}$ 
corresponds to the sodium ( $\mathrm{Na}$ ) KLL Auger peak. The amount of detected residual chloride was minimal $<1$ atom $\%$, confirming the majority $(\sim 80 \%)$ of the $\mathrm{Pd}(2.24$ atom $\%)$ present in the sample (on the fiber surface) was reduced $\mathrm{Pd}^{0}$.

Internally dispersed Pd nanoparticles were subsequently investigated for their catalytic activity in a series of Suzuki cross coupling reactions (Scheme S1). Products were confirmed by GC-MS. 
Scheme S1. List of reaction schemes and outcomes for Pd-catalyzed Suzuki couplings.

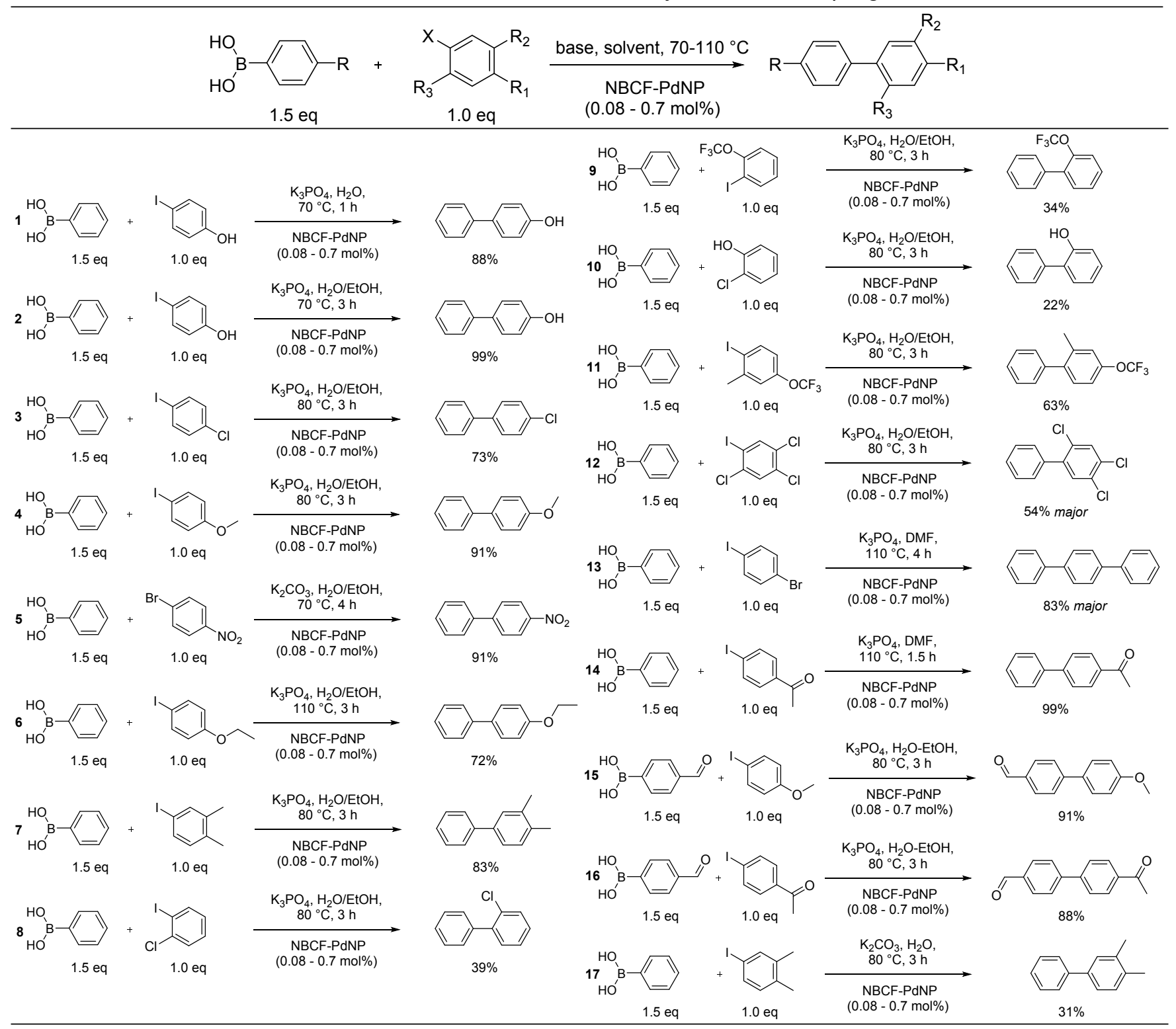

Entry 12 and 13 had unusual reactivity and gave 2-3 minor products in addition to the major product (Scheme S2).

Scheme S2. Minor products of reactions with two or more halide substituents. 

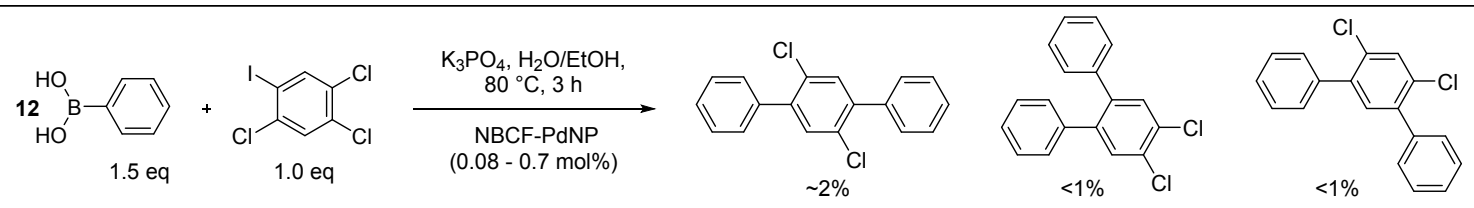

minor products
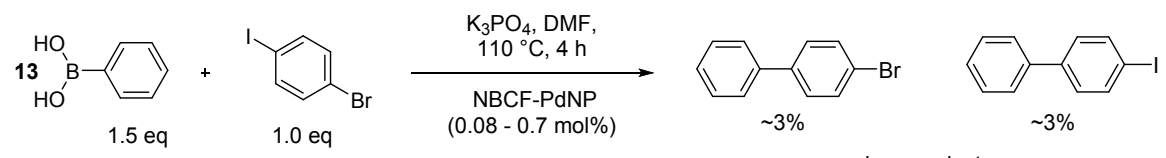

minor products

Yields estimated from GC-MS traces.

The durability and activity of the Pd nanoparticle catalyst was assessed over a series of ten consecutive experiments using experimental entry 2 (Figure S4).

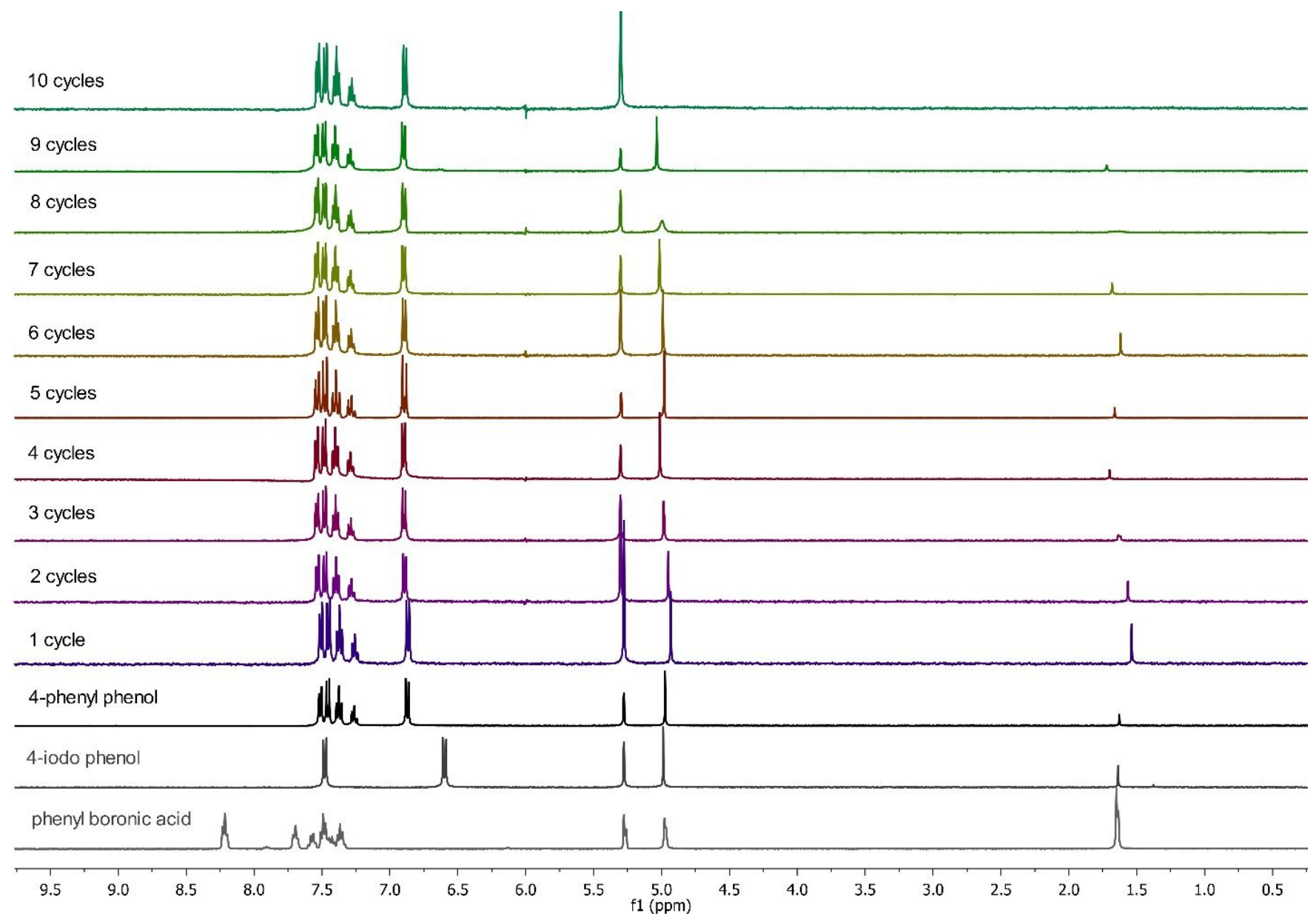

Figure S4. Stack of (from bottom to top) starting materials (phenyl boronic acid, 4-iodo phenol), the authentic commercially supplied product (4-phenyl phenol), and the obtained product after 1-10 cycles using Pd catalyst within brown cotton fibers. 
The product purity was determined by both ${ }^{1} \mathrm{H}$ NMR and ${ }^{13} \mathrm{C}$ NMR, Figure S5 and Figure S6, respectively. While the catalyst-loaded fabric was analyzed before and after visually (Figure S7) and by ICP-MS (Figure S8).

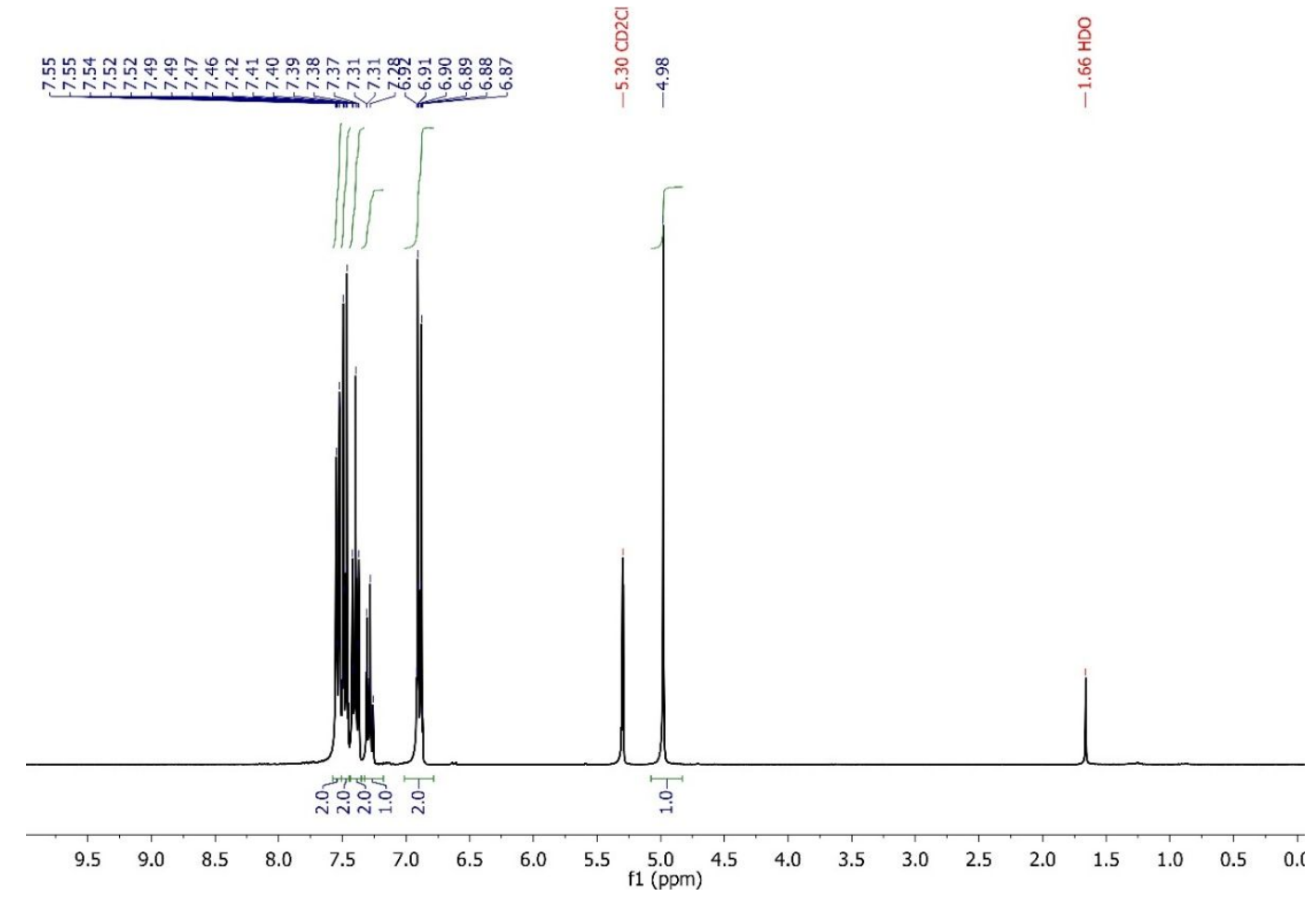

Figure S5. ${ }^{1} \mathrm{H}$ NMR (300 MHz, $\mathrm{CD}_{2} \mathrm{Cl}_{2}$ ) of entry 2 product (p-phenylphenol). $\delta 7.53(\mathrm{dt}, J=8.2,1.9 \mathrm{~Hz}, 2 \mathrm{H}), 7.48$ (dt, $J=8.4,3.0,1.9 \mathrm{~Hz}, 2 \mathrm{H}), 7.40(\mathrm{td}, J=6.9,1.7 \mathrm{~Hz}, 2 \mathrm{H}), 7.28(\mathrm{tt}, J=7.7,1.5,1.1 \mathrm{~Hz}, 1 \mathrm{H}), 6.89(\mathrm{dt}, J=8.8,3.1$, $1.9 \mathrm{~Hz}, 2 \mathrm{H}), 4.98(\mathrm{~s}, 1 \mathrm{H})$. 


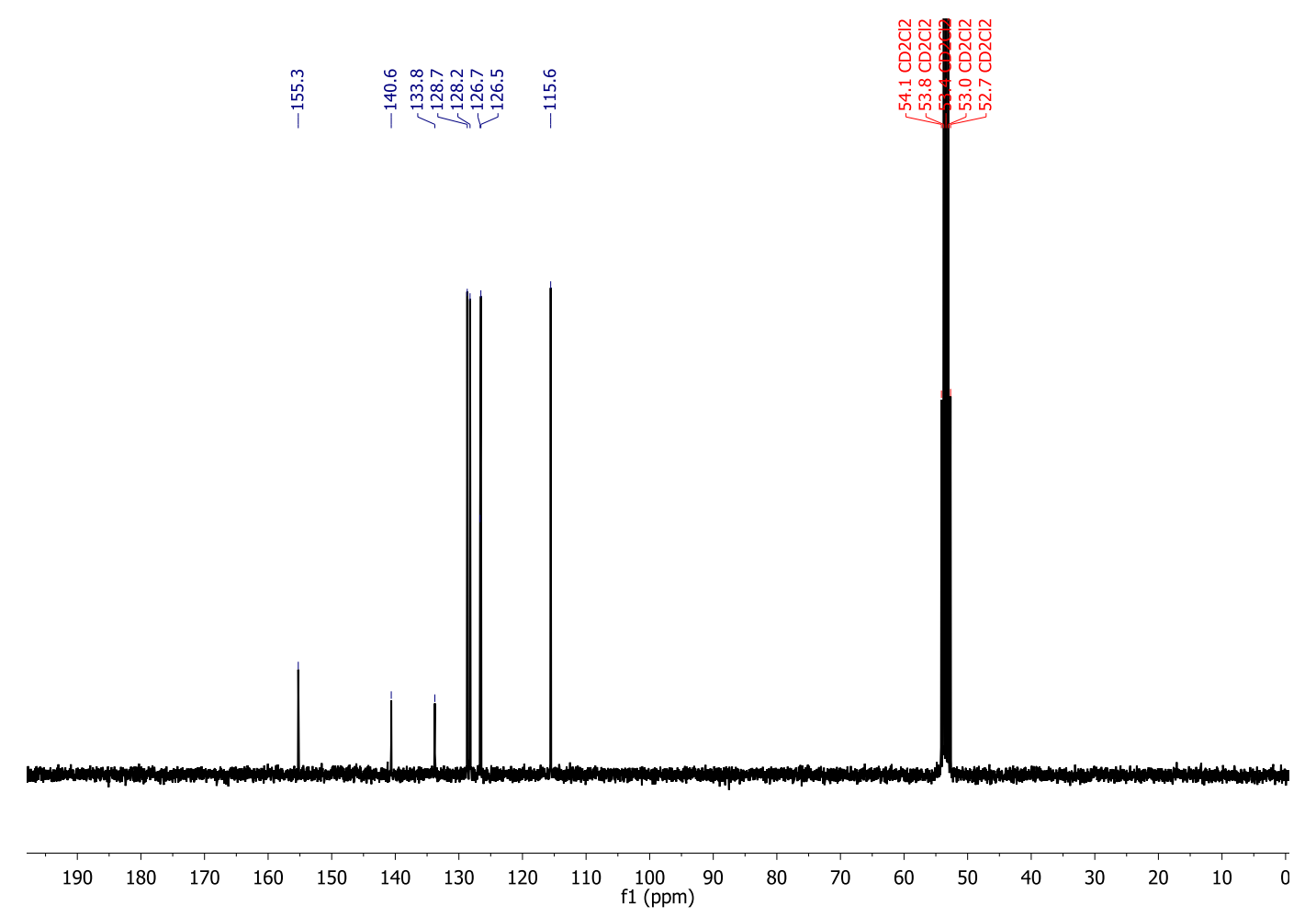

Figure S6. (entry 2) ${ }^{13} \mathrm{C}$ NMR (75 MHz, $\mathrm{CD}_{2} \mathrm{Cl}_{2}$ ) of entry 2 product (p-phenylphenol). $\delta 155.3,140.6,133.8,128.7$, $128.3,126.7,126.5,115.6$

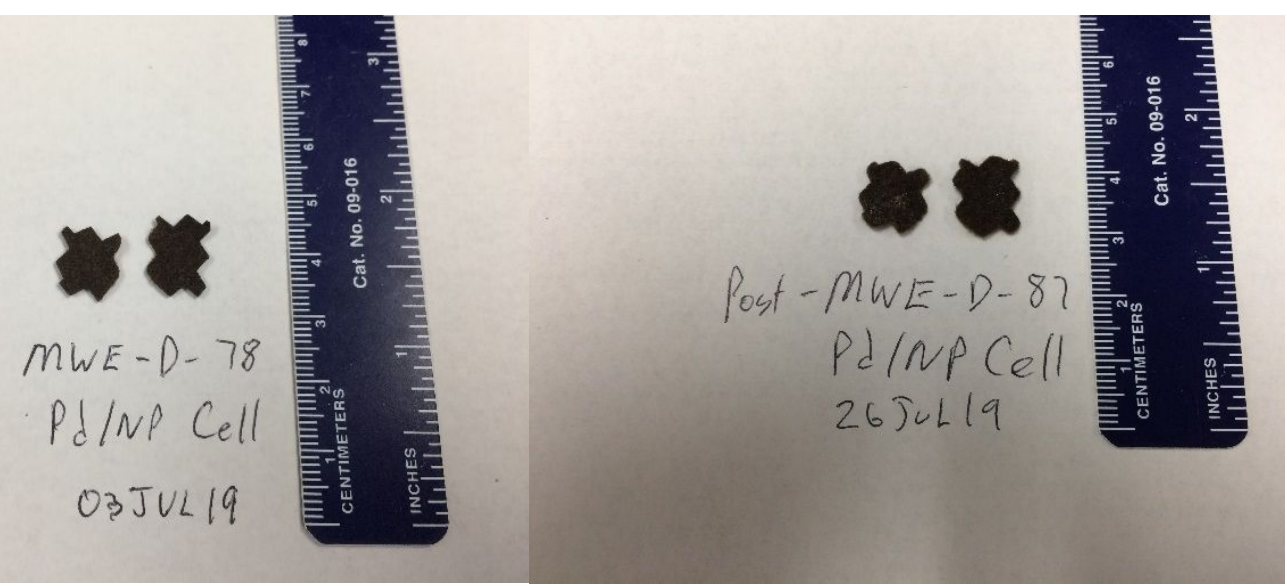

Figure S7. Photos of the palladium nanoparticle-infused NBCF, before (left) and after (right) 10x Suzuki-coupling experiments. Note the scissor cut outlining the substrate. Despite thirty hours of experiments the substrate appears remarkably intact, with only slight rounding of the scissor cut edges. 


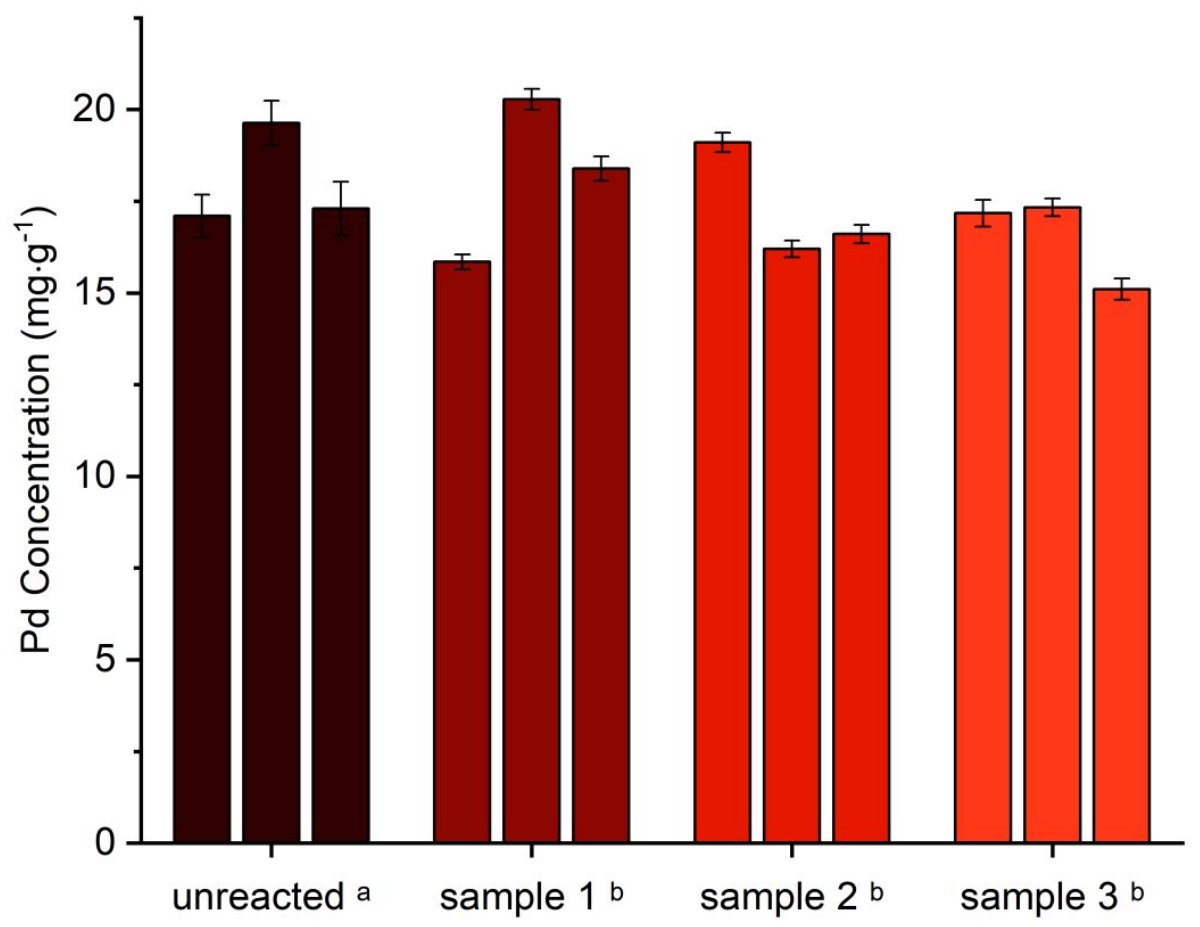

Figure S8. Average palladium (Pd) concentration from ICP-MS in unreacted and treated samples of fabric before (unreacted) and after 10 Suzuki-coupling experiments. a) after loading with PdNP prior to use, and b) after using samples for 10x catalytic reactions. Experiments were performed in triplicate; the error bars are from triplicate measurements of individual samples by ICP-MS. 
Representative GC traces are shown for entries 2, 12, and 13. These were selected as a model reaction (2, Figure S9), and for the reactions that gave multiple products (12, Figure S10, and 13, Figure S11).

Entry 2 (4-OH, biphenyl; MW=170)

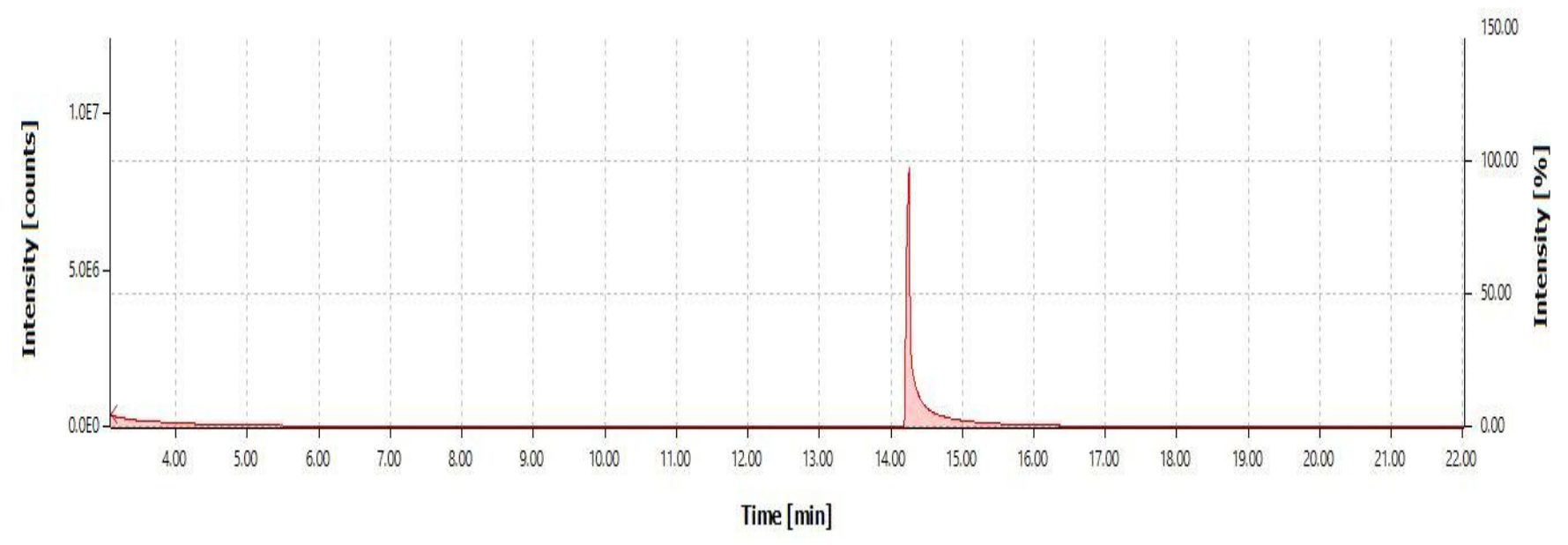

Entry 2 - 14.25 min peak (4-OH, biphenyl)

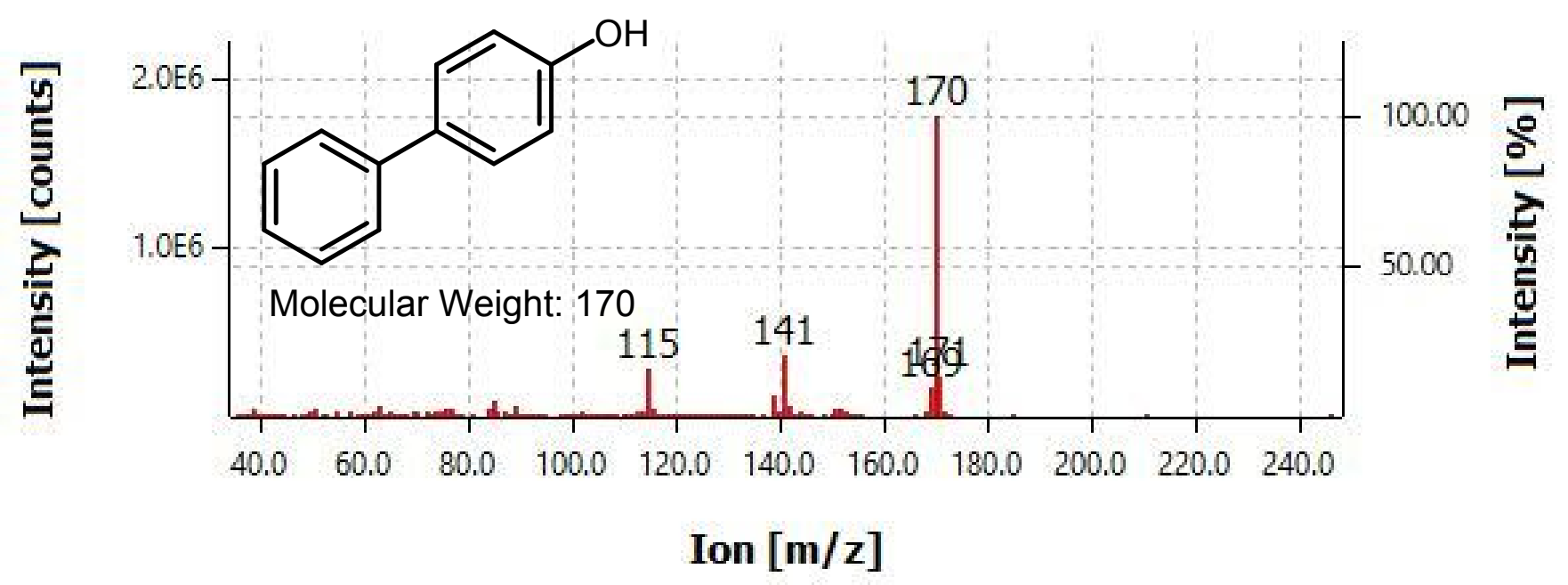

Figure S9. Sample GC-MS trace for entry 2 scaled reaction. 
Entry $12(2,4,5-\mathrm{Cl}$, biphenyl; MW=256)

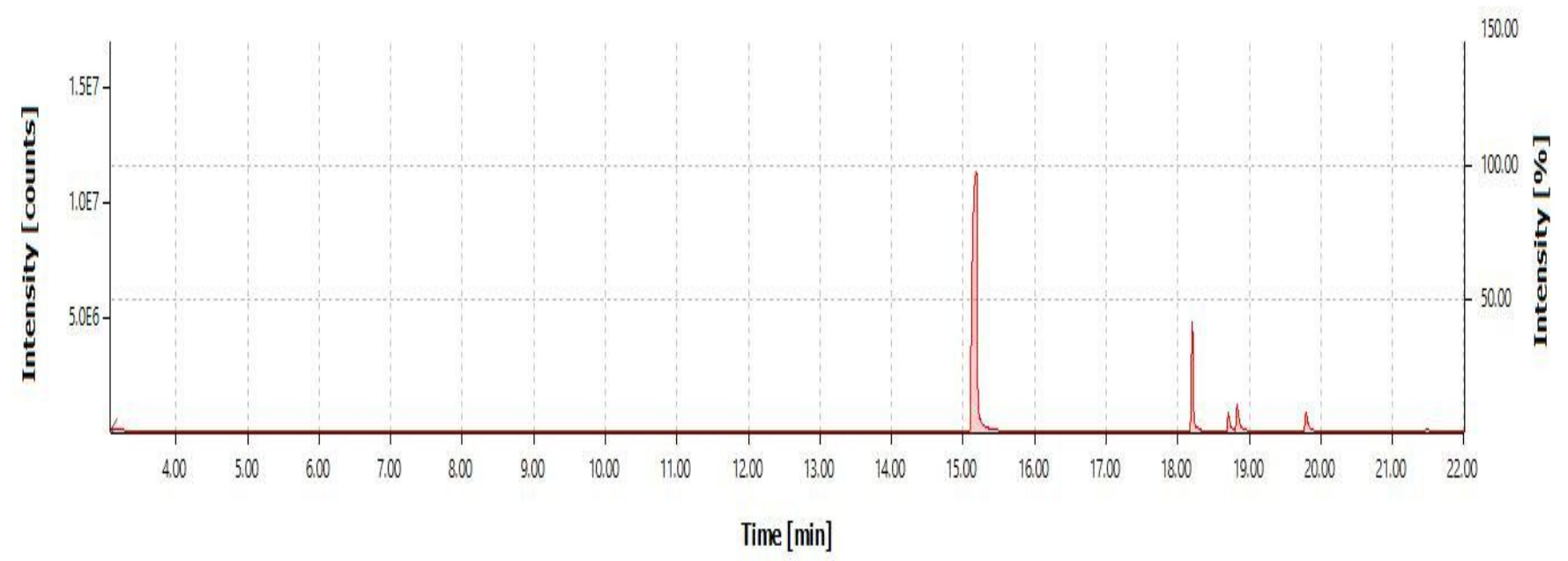

Entry 12 - 15.17 min peak (2,4,5-Cl, biphenyl)

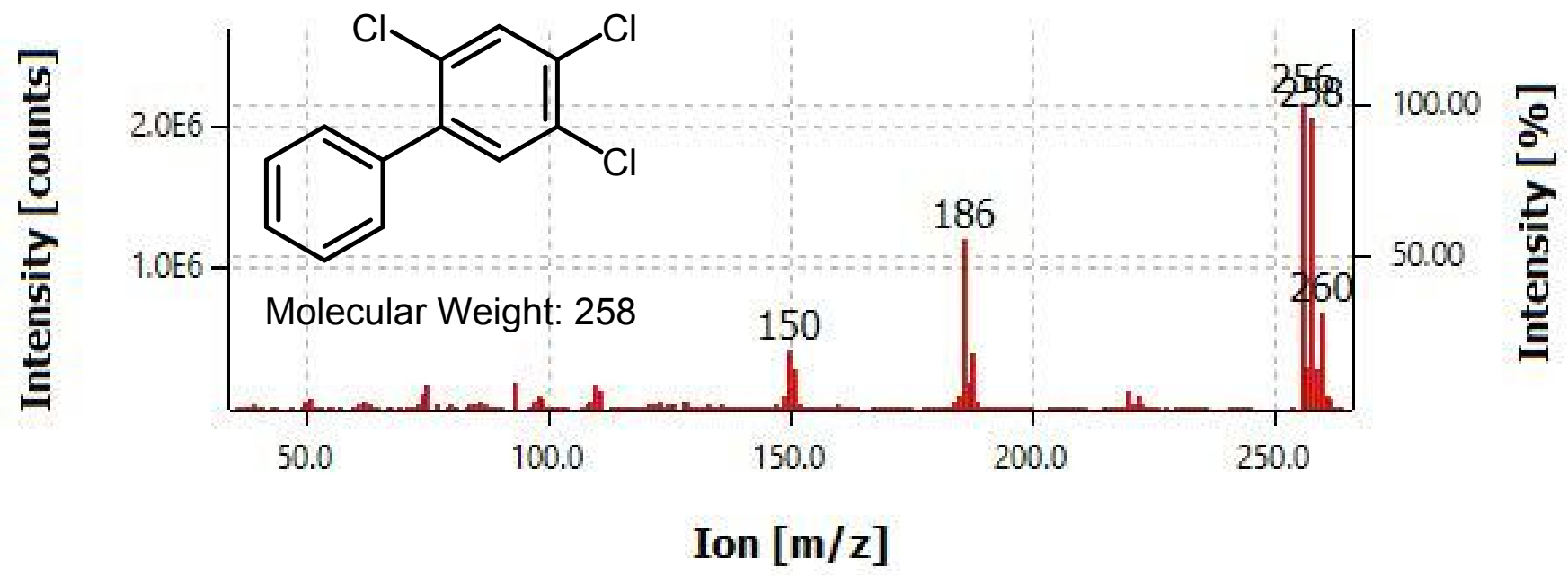

Entry 12 - 18.21 min peak (2,5-Cl,4-Ph, biphenyl; MW=298) 


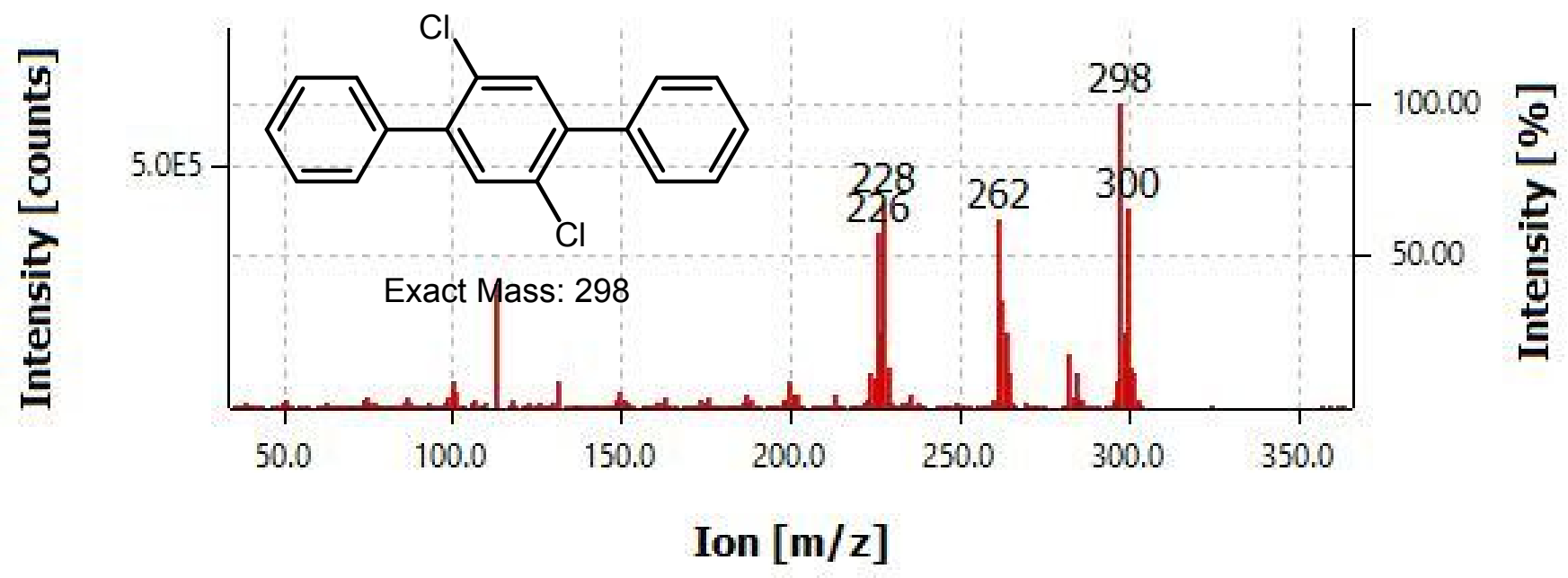

Entry 12 - 18.84 min peak $(2,4-\mathrm{Cl}, 5-\mathrm{Ph}$, biphenyl; MW=298)

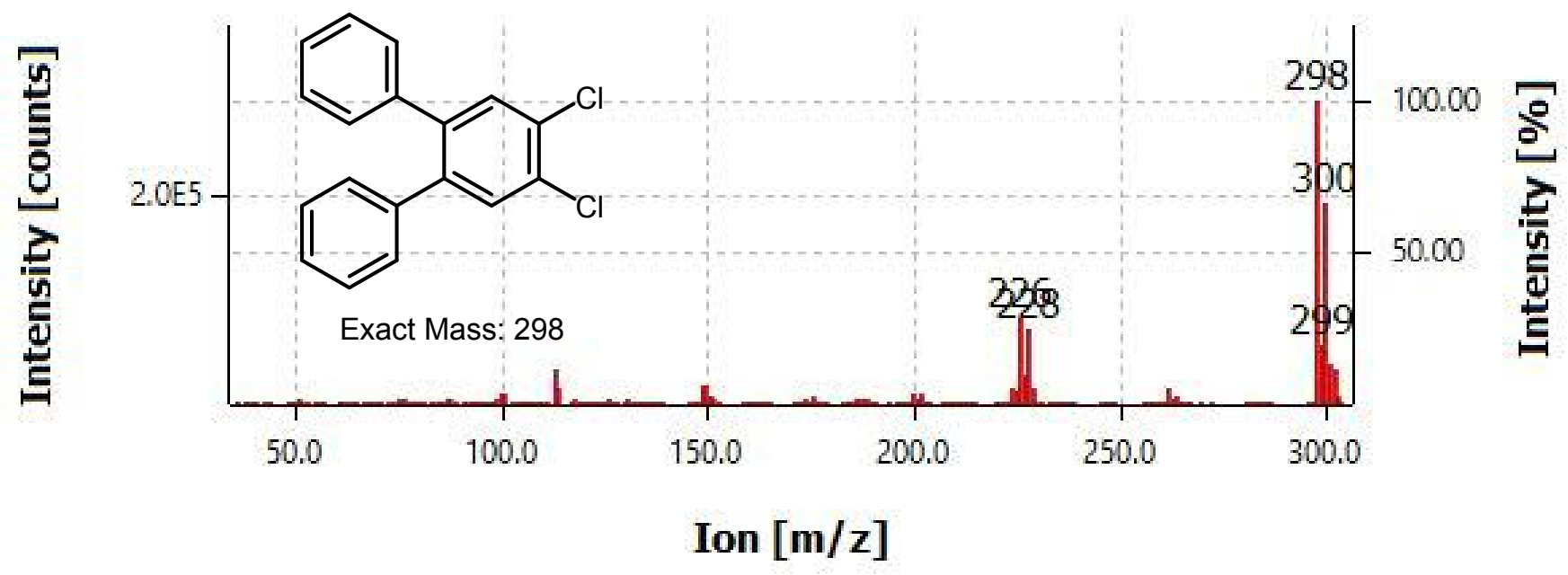

Entry 12 - 18.71 min peak $(4,5-\mathrm{Cl}, 2-\mathrm{Ph}$, biphenyl; $\mathrm{MW}=298)$ 


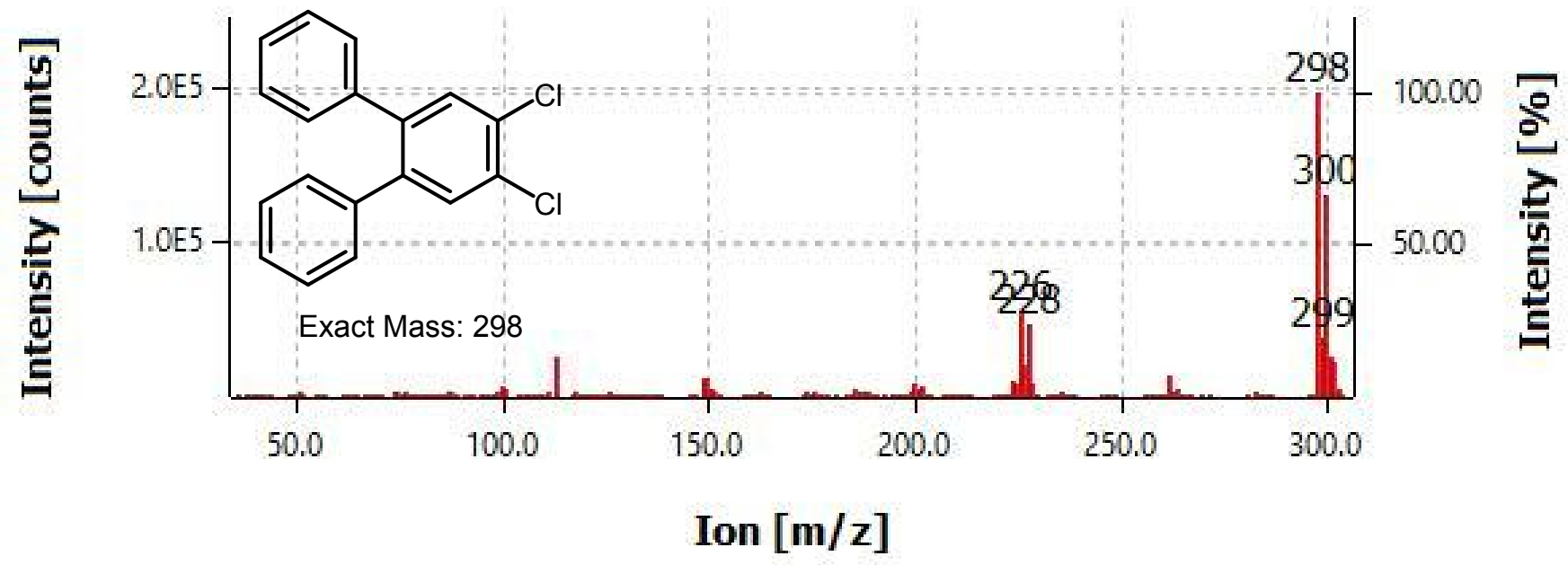

Figure S10. GC-MS traces for entry 12 
Entry 13 (4-Br, biphenyl; MW=232)

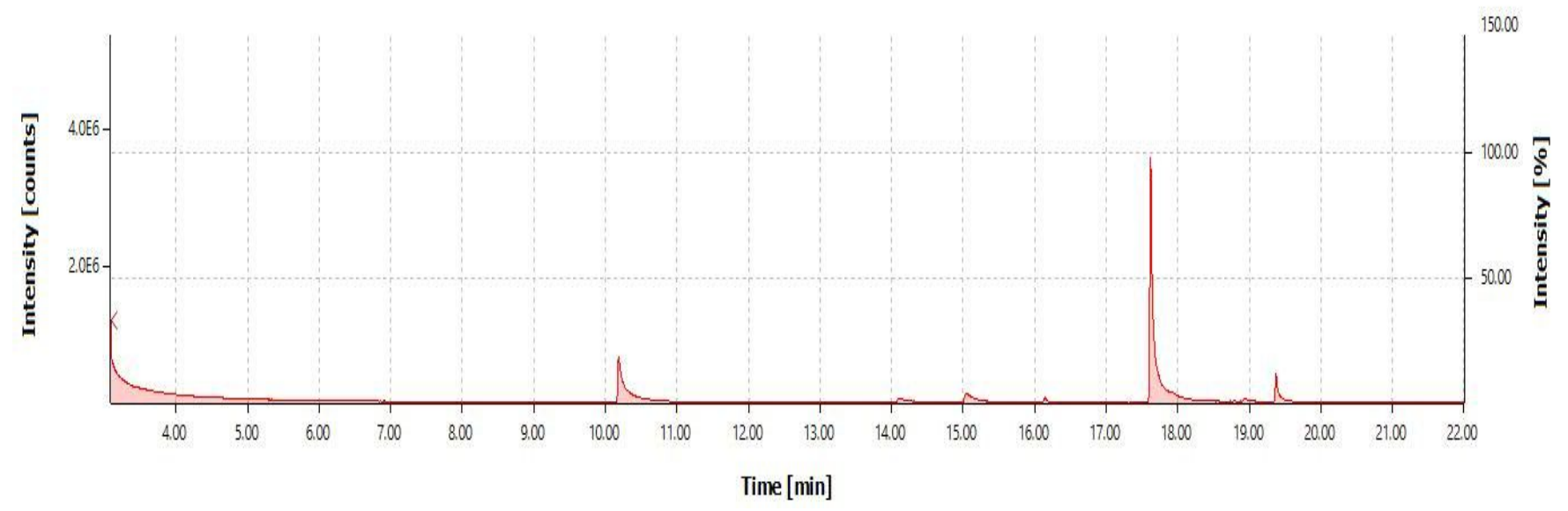

Entry $13-17.63$ min peak (Ph-Ph-Ph; MW=230)

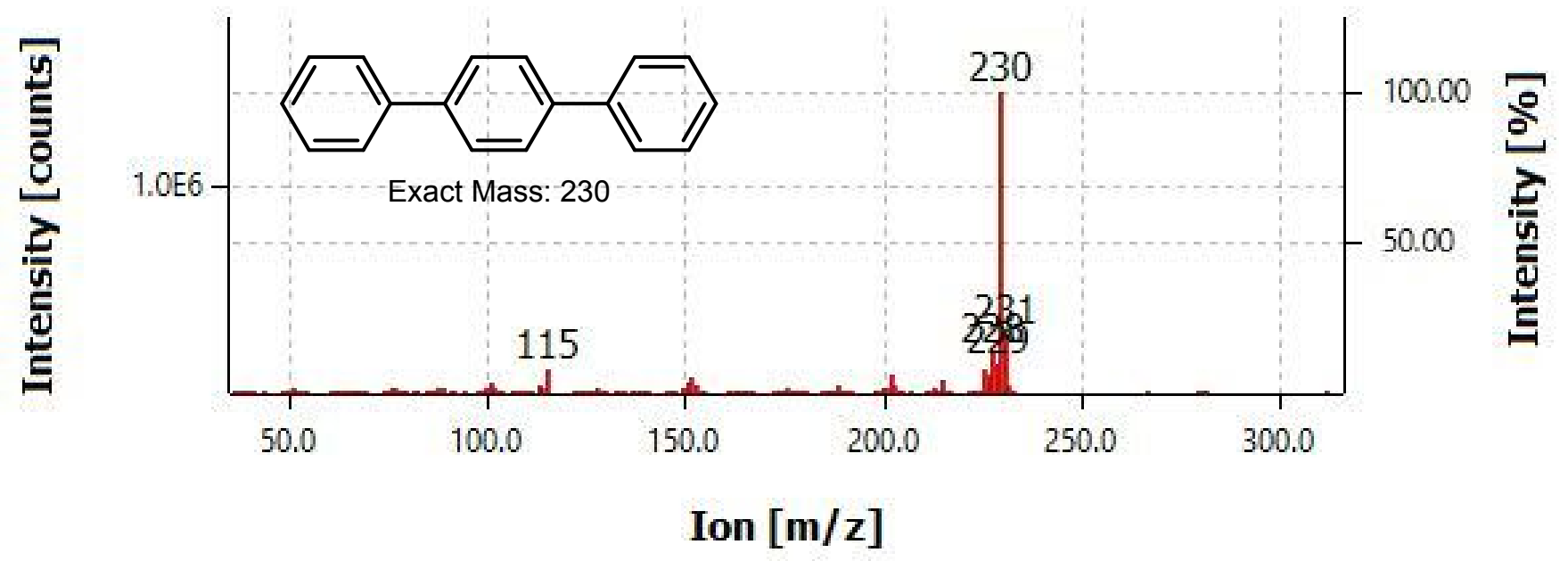

Entry $13-10.20$ min peak $(\mathrm{I}-\mathrm{Ph}-\mathrm{Br} ; \mathrm{MW}=282)$

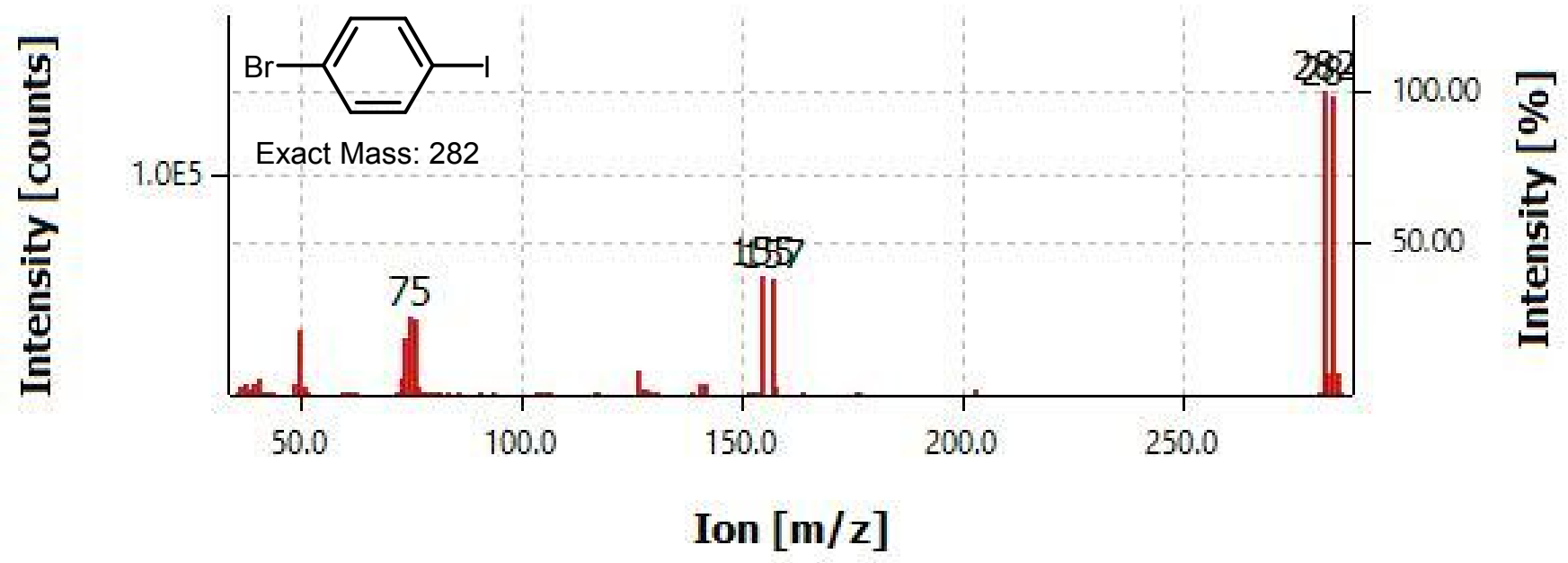


Entry 13 - 19.38 min peak (triphenyl boroxine)

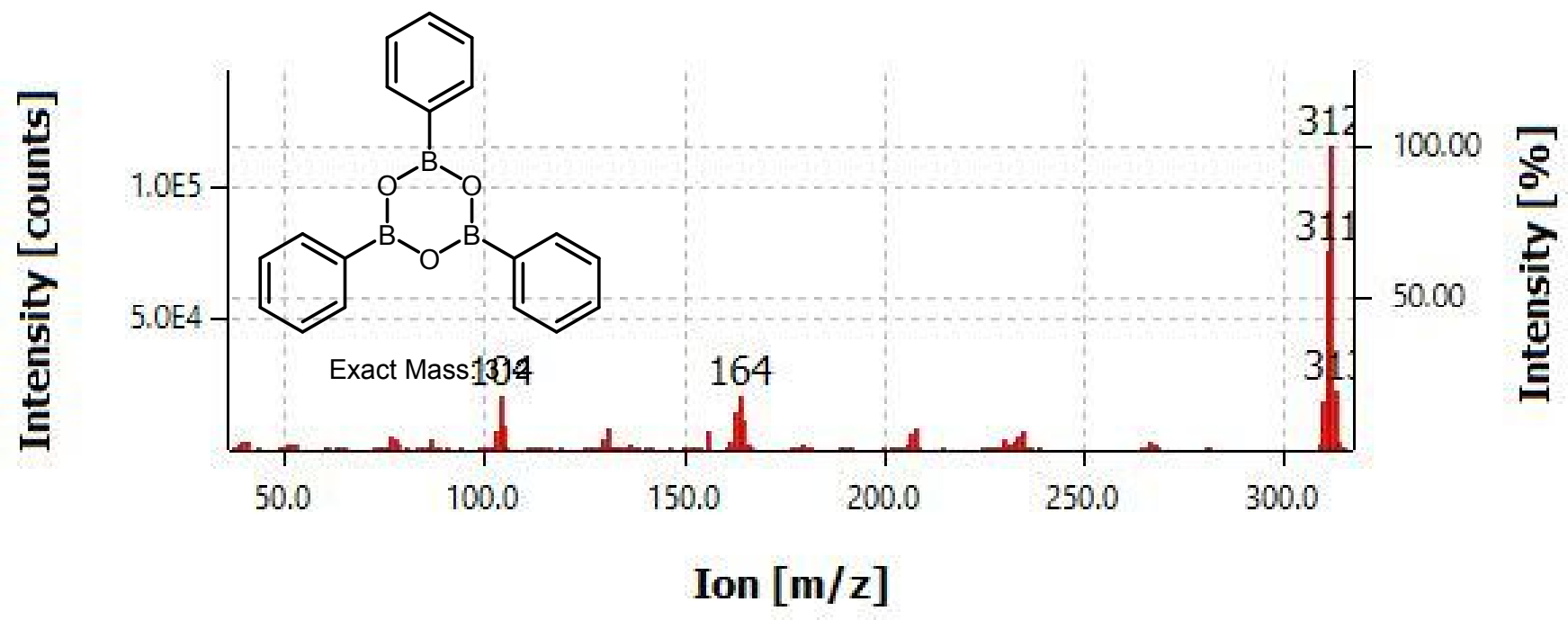

Entry $13-15.05$ min peak (I-Ph-Ph; MW=280)

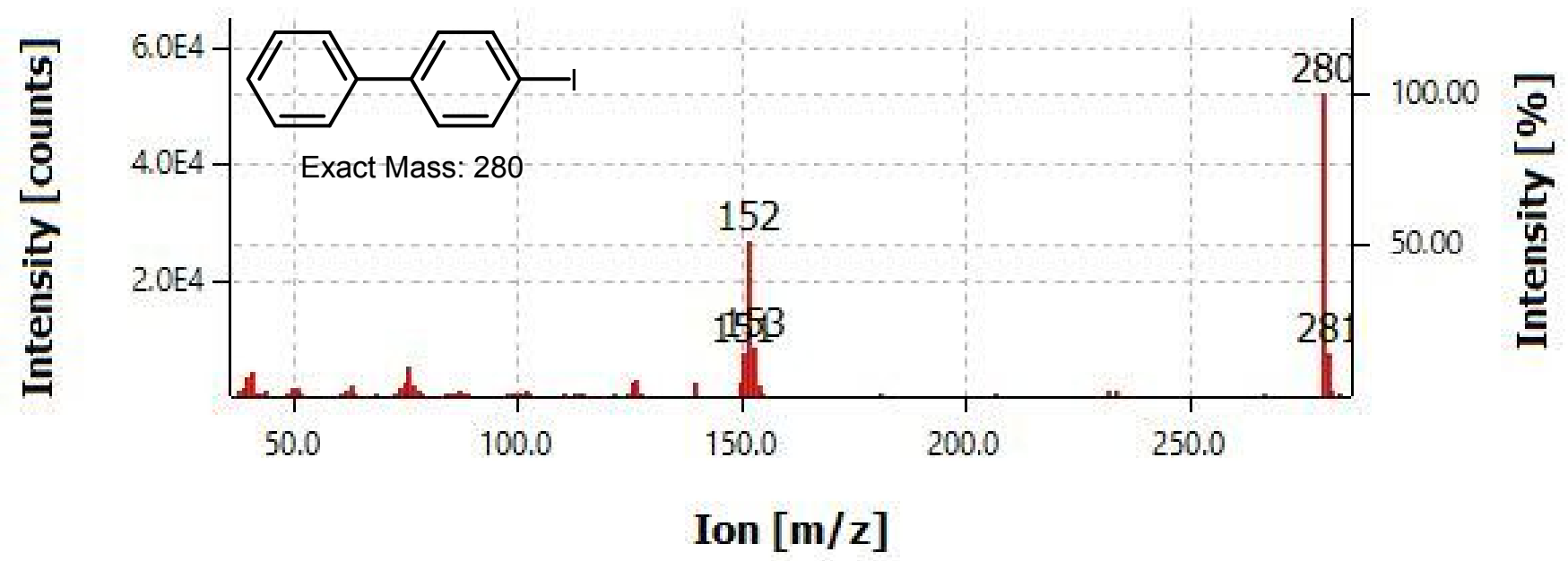

Entry 13 - 14.12 min peak (4-Br, biphenyl) 

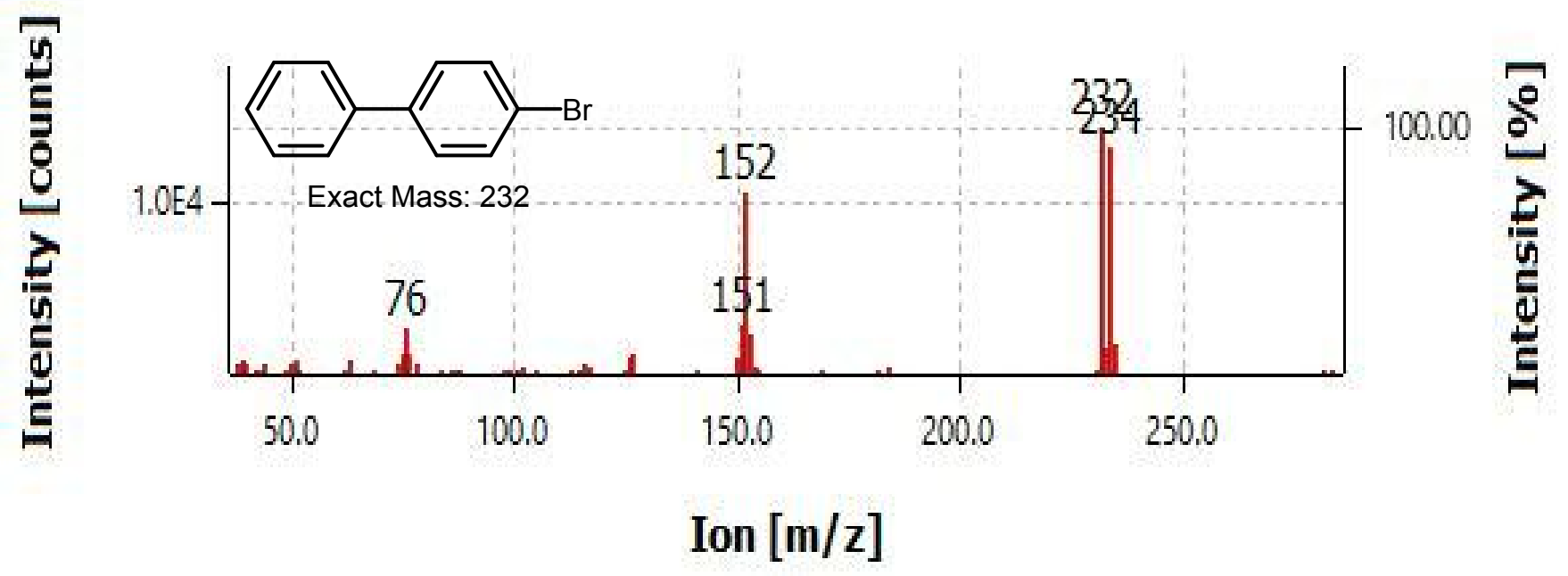

Figure S11. GC-MS traces for entry 13

\section{References}

1) Boylston, E. K.; Hinojosa, O.; Hebert, J. J., A Quick Embedding Method for Light and Electron Microscopy of Textile Fibers. Biotechnic \& Histochemistry 1991, 66 (3), 122-124.

2) Schneider, C. A.; Rasband, W. S.; Eliceiri, K. W., NIH Image to Image J: 25 years of image analysis. Nature Methods 2012, 9 (7), 671-675.

3) Sreedhala, S.; Sudheeshkumar, V.; Vinod, C. P., Structure sensitive chemical reactivity by palladium concave nanocubes and nanoflowers synthesised by a seed mediated procedure in aqueous medium. Nanoscale 2014, 6 (13), 7496-7502.

4) Hong, K.; Sajjadi, M.; Suh, J. M.; Zhang, K.; Nasrollahzadeh, M.; Jang, H. W.; Varma, R. S.; Shokouhimehr, M., Palladium Nanoparticles on Assorted Nanostructured Supports: Applications for Suzuki, Heck, and Sonogashira Cross-Coupling Reactions. ACS Applied Nano Materials 2020, 3 (3), 2070-2103.

5) Chatterjee, S.; Bhattacharya, S. K., Size-Dependent Catalytic Activity and Fate of Palladium Nanoparticles in Suzuki-Miyaura Coupling Reactions. ACS Omega 2018, 3 (10), 12905-12913.

6) Jordan, J. H.; Easson, M. W.; Dien, B.; Thompson, S.; Condon, B. D., Extraction and characterization of nanocellulose crystals from cotton gin motes and cotton gin waste. Cellulose 2019, 26 (10), 5959-5979. 
